\title{
FLORESTAN FERNANDES: ORIGENS DO SUBDESENVOLVIMENTO BRASILEIRO
}

\author{
Eduardo Gomes Maximiliano ${ }^{1}$ \\ Priscila von Dietrich ${ }^{2}$
}

\begin{abstract}
Resumo: Florestan Fernandes (1920-1995) destacou-se por conceber as bases da sociologia brasileira, definindo não apenas o enfoque teórico-metodológico, mas toda a dimensão profissional do cientista social no país. A obra de Florestan é marcada pela preocupação em constituir um pensamento especificamente sociológico das grandes questões nacionais, inserindo-se de modo sui generis na categoria de intérprete do Brasil. Este artigo ordena as principais contribuições do autor sobre a formação da identidade nacional. Após breve apresentação de sua biografia, principais influências e obras publicadas, expomos suas reflexões sobre a trajetória da sociedade brasileira desde o período colonial até a conjuntura do capitalismo dependente. As considerações do autor sobre a problemática do desenvolvimento nacional são apresentadas na segunda parte do texto. A obra de Florestan Fernandes é fundamental para a reflexão sobre o subdesenvolvimento brasileiro, o que lhe confere grande relevância para compreender o período atual e ponderar sobre os desdobramentos da sociedade contemporânea.
\end{abstract}

Palavras-chave: Sociologia; Florestan Fernandes; Desenvolvimento socioeconômico, Interpretações do Brasil.

\section{FLORESTAN FERNANDES: ORIGINS OF BRAZILIAN UNDERDEVELOPMENT}

\begin{abstract}
Florestan Fernandes (1920-1995) is widely recognized for conceiving the bases of Brazilian sociology, defining not only the theoretical-methodological approach, but the entire professional dimension of the social scientist. Fernandes' works are marked by its concern with constituting a specifically sociological thought of major national issues, inserting itself in a sui generis way in the category of Brazil's interpreters. This article presents the main contributions of the author on the formation of national identity. After a brief presentation of his biography, major influences and published works, we expose his reflections on the trajectory of Brazilian society from the colonial period to the conjuncture of dependent capitalism. The author's considerations on the issue of national development are presented in the second part of the text. Florestan Fernandes' works are essential for the studies of Brazilian underdevelopment, which gives it great relevance for understanding the current period regarding development in contemporary society.
\end{abstract}

Keywords: Sociology; Florestan Fernandes; Socioeconomic development; Interpretations of Brazil.

\section{FLORESTAN FERNANDES: ORÍGENES DEL SUBDESARROLLO BRASILEÑO}

Resumen: Florestan Fernandes (1920-1995) es conocido por concebir los fundamentos de la sociología brasileña, definiendo no solo el enfoque teórico-metodológico, sino toda la dimensión profesional del investigador social en el país. El trabajo de Florestan muestra su preocupación por constituir un pensamiento específicamente sociológico de los principales problemas nacionales, insertándose de manera sui generis en la categoría de intérprete de Brasil. Este artículo ordena las principales contribuciones del autor sobre la formación de la identidad nacional. Después de una breve presentación de su biografía, sus principales influencias y trabajos publicados, exponemos sus reflexiones sobre la trayectoria de la sociedad brasileña desde el período colonial hasta la coyuntura del capitalismo dependiente. Las consideraciones del autor sobre el tema del desarrollo nacional se presentan en la segunda parte del texto. Las composiciones de Florestan Fernandes son fundamentales para repensar el subdesarrollo brasileño, lo que le da una gran relevancia para comprender el período actual y considerar las repercusiones en la sociedad contemporánea.

Palabras clave: Sociología; Florestan Fernandes; Desarrollo socioeconómico, Interpretaciones de Brasil.

\section{Introdução}

A questão que orienta este artigo é a reflexão sobre a problemática do subdesenvolvimento a partir das peculiaridades na formação do capitalismo brasileiro. Florestan

\footnotetext{
1 Mestrando no Programa de Pós-Graduação em Desenvolvimento Econômico do Instituto de Economia da Universidade Estadual de Campinas. Bolsista CNPq. E-mail: edugmax@gmail.com

2 Mestranda no Programa de Pós-Graduação em Desenvolvimento Econômico do Instituto de Economia da Universidade Estadual de Campinas. Bolsista CAPES. E-mail: priscila.dietrich@gmail.com
} 
Fernandes tratou o problema através da análise das condições ou barreiras à constituição da ordem social competitiva, conceito de dimensão especificamente sociológica, pensando a questão pela esfera dos processos sociais básicos envolvidos. A ordem social competitiva é característica do modo de produção capitalista, mas encontrou entraves estruturais à sua instituição plena no Brasil. O autor procurou compreender as condições resultantes da dinâmica interna desse modo de organização que inseriram obstáculos à realização da ordem social correspondente. As complicações decorrentes da formação do capitalismo brasileiro passam, necessariamente, pela forma como foram superadas as estruturas econômicas, sociais e políticas estabelecidas sob o regime colonial, isto é, a maneira como se rompeu com a ordem social escravocrata e senhorial e se instituiu progressivamente a ordem social competitiva. Este artigo ordena as principais contribuições do autor sobre a formação da identidade nacional. Após uma breve apresentação de sua biografia, principais influências e obras publicadas, expomos suas reflexões sobre a trajetória da sociedade brasileira desde o período colonial até a conjuntura do capitalismo dependente.

Oriundo das camadas populares de São Paulo, Florestan Fernandes ingressou na Faculdade de Filosofia, Letras e Ciências Humanas da Universidade de São Paulo (FFLCHUSP) em 1941, onde começou sua carreira docente e desenvolveu parte importante de sua produção acadêmica. Foi professor titular na cadeira de sociologia até ser aposentado compulsoriamente pela ditadura militar em 1969, quando se exilou nos Estados Unidos e Canadá e atuou como pesquisador visitante na Universidade de Columbia, professor titular na Universidade de Toronto e professor visitante na Universidade de Yale, aproveitando o período para finalizar o livro A Revolução Burguesa no Brasil: Ensaio de interpretação sociológica. Florestan retornou ao Brasil em 1972 e teve seu reingresso na FFLCH-USP negado, tornando-se professor na Pontifícia Universidade Católica de São Paulo por um curto período antes de iniciar sua carreira política. Como descrito por Maria Arminda do Nascimento Arruda, esses momentos singulares correspondem às fases de ruptura e reconstituição na vida do autor, "vincadas pela metamorfose do menino pobre em professor da Universidade de São Paulo, e do sociólogo reconhecido que perdera o espaço privilegiado, lugar de excelência onde depositara as apostas profissionais e afetivas de sua existência" (ARRUDA, 2010, p. 14). Com o término do regime militar, foi eleito deputado constituinte pelo Partido dos Trabalhadores e reelegeu-se para a Câmara em 1990. O autor faleceu em 1995 após complicações cirúrgicas, deixando um legado imensurável à pesquisa sociológica no Brasil e na América Latina.

Florestan Fernandes foi responsável pela afirmação da sociologia como disciplina científica empírica, definindo métodos de pesquisa com extremo rigor e clareza. Sua obra foi influenciada por Durkheim na função de sociólogo e agente ativo, capaz de tomar posição e 
promover uma intervenção racional na realidade social (COHN, 1986). A questão de intervir ativamente, sobretudo no controle e planejamento democrático, o conecta à Mannheim, autor que serviu de apoio para sua análise das dimensões ideológicas e utópicas do liberalismo (ARRUDA, 2010). Ao examinar uma sociedade capitalista essencialmente contraditória, fruto de uma revolução burguesa frustrada, Florestan se deparou com problemas similares aos que Max Weber estudou na Alemanha ao início do século XX. O autor também é associado a Marx por unificar linhas de pensamento distintas no esforço de sua investigação, trabalhando no plano das construções teóricas e distinguindo os princípios da análise de seus desdobramentos políticos. A busca pela intervenção o aproximou de Lenin ao constatar a ausência não apenas de uma burguesia plenamente capitalista, mas do partido socialista revolucionário, agente da grande opção histórica em relação à realidade observada pelo autor.

Florestan Fernandes publicou mais de cinquenta livros e centenas de artigos ao longo de sua carreira. Algumas de suas principais obras estão situadas a seguir, com destaque àquelas de maior relevância para o escopo deste artigo. As primeiras grandes contribuições do autor foram A organização social dos Tupinambá (1949) e A função social da guerra na sociedade Tupinambá (1952), resultado de sua dissertação de mestrado e tese de doutoramento sob a orientação de Roger Bastide. Ao longo das décadas de 1940 e 1950, Florestan e Bastide dirigiram uma extensa pesquisa sobre as relações raciais no Brasil financiada pela Unesco. Seus trabalhos deram origem aos livros: Brancos e Negros em São Paulo, assinado por ambos em 1955 e ampliado em 1959; A integração do negro na sociedade de classes, apresentado como tese de cátedra de Florestan Fernandes em 1964; e O negro no mundo dos brancos, publicado pelo autor em 1972. Sua reflexão sobre a problemática do desenvolvimento tomou forma em Sociedade de classes e subdesenvolvimento (1968), Capitalismo dependente e Classes Sociais na América Latina (1973) e Circuito Fechado: Quatro ensaios sobre o "poder institucional" (1976). Sua obra mais conhecida, A Revolução Burguesa no Brasil: ensaio de interpretação sociológica (1975), marca um importante ponto de inflexão na produção literária de Florestan, momento em que deixou de lado a formalidade da dissertação científica para redigir um ensaio, forma que criticara avidamente enquanto professor da Universidade de São Paulo. Suas últimas obras de grande expressão foram Da guerrilha ao socialismo: A revolução cubana (1979), O que é revolução? (1981) e Poder e contrapoder na América Latina (1981), redigidas poucos anos antes de Florestan ingressar na arena política.

\section{Da colonização ao capitalismo dependente}

A ordem social escravocrata e senhorial, instaurada sob a égide do regime colonial, moldou a formação da sociedade brasileira e determinou as proporções e o alcance dos 
dinamismos econômicos absorvidos após a independência. Conforme apresentado por Florestan Fernandes (2005), o Brasil constitui um caso ideal para o estudo das relações entre escravidão e desenvolvimento capitalista. O caráter universal assumido pelo trabalho escravo condicionou todos os desdobramentos históricos desde o início da colonização até o advento da modernização burguesa. Fernandes (2005) descreve a escravidão como processo de acumulação primitiva brasileira e base principal do capital mercantil, de modo que o escravo assumia o papel de mercadoria fundamental em uma vasta rede de negócios. Ao analisar a sociedade escravista no Brasil, o autor propôs a seguinte periodização: era colonial, caracterizada pelo domínio da Coroa e pelos efeitos do pacto colonial; era de transição neocolonial, correspondente ao intervalo entre a abertura dos portos e a década de 1860; e a era de emergência e expansão do capitalismo dependente, que se configurou em uma economia urbano-comercial satelitizada em relação ao meio rural a partir de 1860, mas engendrou uma economia urbano-industrial capitalista responsável pela posterior integração nacional.

A articulação entre Colônia e Metrópole fundava-se na rede de negócios estabelecida pela organização do trabalho escravo. O caráter mercantil da escravidão permitia que o capital penetrasse em formas de produção pré-capitalistas, conexão que se aprofundou com o tráfico africano e a universalização do trabalho escravo. O pacto colonial garantia que a realização do excedente ocorresse fora da Colônia, enquanto a extração de mais-valor absoluto era ampliada por uma divisão do trabalho rudimentar que combinava a labuta escrava, livre e semilivre. $\mathrm{O}$ excedente econômico era produzido para que os agentes se inserissem no circuito de acumulação mercantil, onde senhor, Coroa e negociantes estavam no mesmo patamar. A escravidão preservou seu caráter mercantil na era de transição neocolonial e de formação do capitalismo dependente, o que acarretou na consolidação de todas as suas ligações estruturais e dinâmicas, possibilitando ao senhor dispor livremente do produto do trabalho escravo. A vinda da Coroa para o Rio de Janeiro proporcionou a formação de vínculos diretos entre a economia de plantação e o comércio interno com o mercado mundial. Consequentemente, a internalização do tráfico e do excedente produzido pelo trabalho escravo fortaleceram a ordem escravocrata e senhorial, permitindo que alcançasse todas as potencialidades sociodinâmicas que não podiam ser exercidas sob o regime colonial.

O caráter contraditório do processo deriva da dupla função assumida pela escravidão mercantil: ao mesmo tempo que serviu como base material da revitalização do latifúndio e perpetuou as estruturas de produção pré-capitalistas, também foi fator essencial para o acúmulo de excedentes mercantis nas cidades, requisito elementar para a evolução urbano-comercial ocorrida ao longo do século XIX. Desta forma, Fernandes (2005) revela a relação dual entre escravidão e modernização capitalista no Brasil. A evolução do modelo baseado na exploração 
do trabalho escravo alcançara tal grau de diferenciação que exigiu outras formas de trabalho, atingindo seu apogeu com a instituição do trabalho livre após 1888. A internalização do excedente produzido pelo trabalho escravo resultou no desenvolvimento interno do capitalismo, relacionando a produção rural arcaica com o urbano-comercial integrado ao mercado mundial, culminando na abolição da escravatura e na substituição do trabalho escravo pelo imigrante. A ordem escravocrata e senhorial foi destruída endogenamente, pelo desenvolvimento capitalista engendrado pela economia escravista, ao mesmo tempo que foi transformada por fatores externos, decorrente da difusão da economia urbano-comercial para a área rural. Conforme descrito pelo autor:

A ordem escravocrata e senhorial foi destruída a partir de dentro, através de desenvolvimentos capitalistas direta ou indiretamente engendrados pela economia de plantação escravista; e foi, ao mesmo tempo, suplantada $e$ substituída a partir de fora, pelos desenvolvimentos capitalistas que se irradiaram da economia urbano-comercial para a sua periferia agrária. Trata-se de um circuito histórico bem conhecido. Apenas, no Brasil, ele não se deu de maneira completa. Como o polo senhorial do regime monárquico logrou converter-se no polo oligárquico do regime republicano, graças a certas condições materiais e políticas que permitiram essa rotação histórica, ao desaparecer, o trabalho escravo deixou atrás de si várias formas de trabalho semilivre e de trabalho escravo disfarçado que continuam a existir até hoje, mesmo em economias de plantação tidas como "especificamente modernas". (FERNANDES, 2005, p. 70, grifos do autor).

O modo de produção capitalista foi introduzido no Brasil antes que a ordem social competitiva fosse estabelecida, defrontando-se com estruturas parcialmente adaptadas aos padrões exigidos pelo sistema. A ruptura com o regime colonial possibilitou a adaptação aos dinamismos do mercado mundial, mas preservou o controle político de decisões econômicas internamente. Isto permitiu reorganizar o mercado colonial no que tange as relações com o exterior, mas condicionou a expansão interna do capitalismo aos interesses da aristocracia agrária. Florestan Fernandes (1976) afirma que o processo de modernização capitalista se estabeleceu pela integração ao mercado mundial, mas as consequências do confronto foram definidas por estruturas internas, de modo que o desenvolvimento da ordem social competitiva se efetivasse à medida que a ordem social escravocrata e senhorial se desintegrava.

A revolução burguesa iniciou-se conservando o que havia de essencial nas estruturas sociais arcaicas, mas direcionava-se para uma organização institucional voltada aos interesses da produção (FERNANDES, 1976). Os senhores não eram capazes de impedir o processo de modernização, mas manipulavam suas consequências internas por meios que estavam ao seu alcance. A forma típica de privatismo econômico convertia a iniciativa privada em privilégios estamentais que eram preservados acima de qualquer racionalidade inerente aos processos em curso. A competição só se tornou uma influência construtiva quando a decomposição da ordem 
senhorial atingiu seu clímax, momento que a crise do trabalho escravo se tornou elemento inexorável e impediu qualquer solução "dentro da ordem". A abolição da escravatura decorreu da problemática histórica das elites, que precisavam destruir a escravidão para remover seus entraves à expansão interna do capitalismo - garantindo novas condições de desenvolvimento econômico, social e político - de forma a viabilizar a acumulação capitalista e preservar seus privilégios estamentais.

Florestan Fernandes (1976) descreve a emergência da competição como um processo ambíguo, pois agiu como fator destrutivo para o equilíbrio da ordem social vigente ao mesmo tempo que expandiu o poder de ação do agente econômico favorecido. O comportamento das elites se alterou sem arriscar sua posição privilegiada, mas isso comprometeu a organização escravista da sociedade. Ao operar como fator de fortalecimento de privilégios, a competição se vinculou a processos que dificultaram o desenvolvimento do regime de classes no Brasil, perpetuando relações sociais pré-capitalistas e conservando elementos arcaicos ao invés de eliminá-los. Desta forma, o advento da competição acelerou a dissolução da ordem escravocrata e senhorial em um primeiro momento, mas restringiu a expansão do capitalismo posteriormente, preservando o passado no presente. $\mathrm{O}$ autor esclarece essa contradição em A revolução burguesa no Brasil:

Se a competição concorreu, em um momento histórico, para acelerar a decadência e o colapso da sociedade de castas e estamentos, em outro momento ela irá acorrentar a expansão do capitalismo a um privatismo tosco, rigidamente particularista e fundamentalmente autocrático, como se o "burguês moderno" renascesse das cinzas do "senhor antigo". Em outras palavras, ela engendra uma ordem social em que, além da desigualdade de classes, conta poderosamente o privilegiamento dos privilegiados na universalização da competição como relação e processo sociais. Em consequência, a ordem social competitiva resultante é pouco agressiva na quebra das barreiras à expansão do regime de classes e muito moderada na irradiação e imposição dos novos padrões de relações de classe, como se temesse a "racionalidade burguesa" e devesse acolher para sempre os critérios anticompetitivos do velho mundo senhorial (FERNANDES, 1976, p. 168, grifos do autor).

O dilema apresentado por Florestan Fernandes em A Revolução Burguesa no Brasil trata do florescimento da democracia no sistema capitalista. Nessa perspectiva, as instituições democráticas resultam de uma ordem social que assegure a possibilidade de uma trajetória individual aberta ao mérito. $\mathrm{O}$ autor constata que o desenvolvimento histórico da sociedade brasileira não engendrou uma burguesia capaz de levar a fundo a constituição do capitalismo (COHN, 1986). Entretanto, a sociedade se organizou em termos capitalistas e isso exige a presença dominante de uma classe burguesa que não foi plenamente constituída. A questão refere-se à forma que uma sociedade estamental e de castas se transformou em um regime de classes, esbarrando em um problema crucial: como os membros de uma sociedade escravocrata, 
que identificam a liberdade pelo "não-trabalho", passam a se identificar pela atuação profissional dentro da ordem social competitiva.

Portanto, não se configura historicamente, dessa perspectiva, a existência de uma "burguesia" plenamente integrada e consciente do seu destino histórico, que pudesse afirmar-se como portadora de uma consciência especificamente revolucionária. A realidade mostra-nos o inverso disso, pois o plano no qual a ação daqueles estratos sociais era profunda e incoercivelmente inovadora, eles pretendiam uma evolução com a aristocracia agrária e não contra ela (o que destituía o ímpeto decorrente da "revolução dentro da ordem" de qualquer esfera política). (FERNANDES, 1976, p. 186, grifos do autor).

Em A integração do negro na sociedade de classes (FERNANDES, 2008a), Florestan apresenta a abolição como um processo incompleto ao analisar a situação do negro na cidade de São Paulo. A observação da herança escravista evidencia o preconceito racial como fator estrutural das relações sociais consequentes ao desenvolvimento da ordem social competitiva. $\mathrm{O}$ autor descreve o processo de adaptação do negro na nova ordem, como acontece sua inclusão na sociedade de classes e as perspectivas de progresso social a partir de 1930. Os mecanismos de exclusão e a falta de formação profissional reduziam as oportunidades de ascensão de descendentes de escravos, agravando um processo de pauperização e anomia social - conceito durkheimiano referente a desorganização e desintegração social e psíquica (FREITAG, 2005). Durante as primeiras décadas após a abolição, o trabalho assalariado era visto como um desdobramento e prolongamento da escravidão tanto para homens livres, quanto para exescravos e patrões (FERNANDES, 1976). A ampla disponibilidade de mão de obra imigrante concebida como classe trabalhadora assalariada - reforçava a situação, dificultando o acesso dos negros aos mecanismos de ascensão como a formação escolar, o voto democrático e a realização pelo trabalho. Os descendentes de escravos foram afastados sistematicamente de qualquer forma de inclusão na ordem social competitiva, emergindo na cena histórica como agentes de trabalho pré-capitalista, o que estimulava a perpetuação crônica de sua condição estigmatizada de pauperismo e anomia social. De acordo com Florestan Fernandes:

A sociedade de classes colocou a "população de cor" paulistana diante de uma duríssima alternativa. Ou os seus componentes absorviam as técnicas culturais, os padrões de existência e os valores sociais em que ela se fundava - e então teriam elementos para superar, por conta própria, os inconvenientes da anomia, do pauperismo e da inércia sociocultural. Ou eles se condenavam a eternizar aquele estado de coisas, identificando-se, como categoria social, através das características sociopáticas estigmatizantes do estilo de vida a ele correspondente. Empregando-se um eufemismo de linguagem, poder-se-ia dizer que a sociedade de classes abriu as suas portas aos "homens de cor" sob a condição de que se mostrassem capazes de enfrentar e de resolver os seus problemas de acordo com o código ético-jurídico que ela instituía. Mas, na realidade, ela transferiu para os ombros deles a pesada tarefa de prepararem, sozinhos, a "redenção da raça negra". (FERNANDES, 2008a, p. 298). 
O deslocamento do centro dinâmico da economia brasileira após 1930 proporcionou oportunidades reais de integração do negro na sociedade de classes. A análise de Florestan propõe determinar a intensidade com que os efeitos da expansão da ordem social competitiva contribuíram para a democratização das relações sociais no Brasil (FERNANDES, 2008b). O desenvolvimento da economia de mercado e da sociedade de massas, decorrentes do processo de industrialização, tornaram viáveis as possibilidades de inserção do negro no mercado de trabalho livre. A política trabalhista nacional foi particularmente importante ao estabelecer o salário mínimo, medida que garantiu equidade na competição salarial entre os estratos da classe trabalhadora envolvidos nos mesmos níveis ocupacionais. A expansão do número de postos de trabalho coincidiu com a ausência de correntes imigratórias volumosas, inaugurando uma era de superação do estado de pauperização e anomia social. O surgimento de oportunidades de emprego e engajamento à vida socialmente ativa foi concomitante às predisposições de mobilidade social vertical, fortalecendo uma compulsão específica de melhora na condição socioeconômica dos descendentes de escravos. Florestan Fernandes (2008b) constata que a ascensão social da população negra se processou a partir da década de 1930 apesar do preconceito racial, reforçando que os entraves às tendências de mobilidade social operantes no meio negro são decorrentes do racismo estrutural preservados na ordem social competitiva. O autor apresenta o seguinte diagnóstico para a problemática da integração do negro na sociedade de classes:

Tudo isso, todavia, não significa que as avaliações etnocêntricas e os procedimentos discriminativos tenham sido eliminados. Eles persistem, às vezes de forma atenuada ou redefinidos socialmente; e interferem nas relações entre "negros" e "brancos". Em consequência da monopolização do poder pela "raça" branca, ela controla as situações de classe plenamente configuradas pelo grau de desenvolvimento alcançado pela ordem social competitiva em São Paulo. O que quer dizer que as interferências de teor etnocêntrico e discriminativo dos "brancos" prejudicam, irremediavelmente, a "população de cor". Em suma, os dados apresentados não validam a hipótese de que a ascensão social do negro e do mulato, dos últimos anos, encontram explicação na ausência ou quebra do "preconceito de cor". Ao contrário, eles mostram que a ascensão social dos "homens de cor" está se processando apesar da presença sintomática do "preconceito de cor". Além disso, indicam, complementarmente, que algumas das manifestações deste último se associam, definitivamente, ao solapamento das tendências de mobilidade social vertical operantes no "meio negro". (FERNANDES, 2008b, p. 300).

A falta de elasticidade da ordem social escravocrata e senhorial implicou em um longo período de transição para que a ordem social competitiva se instaurasse no Brasil. De acordo com Florestan Fernandes (1976), a vagarosa passagem do regime colonial para o neocolonial desembocou em um padrão capitalista de crescimento econômico dependente e de 
subdesenvolvimento. $\mathrm{O}$ florescimento das cidades proporcionou a formação de um mercado capitalista moderno, ainda que adaptado às condições de um país predominantemente rural. $\mathrm{O}$ autor argumenta que o meio urbano constituiu um bastião interno dos dinamismos econômicos controlados pelos centros hegemônicos da economia mundial, desempenhando a função de mercado satélite responsável por captar parte do excedente econômico remetido aos países centrais. O conflito político que caracterizou a revolução burguesa no Brasil girava em torno da modernização institucional em oposição à manutenção do status quo nos limites dos interesses senhoriais. Os fins convergentes do processo restringiram-se a conter a subordinação à dominação externa em níveis econômicos e técnicos, impedindo que o desenvolvimento se convertesse em um novo pacto colonial, mas sem proporcionar a formação de um capitalismo autossustentado e hegemônico. O resultado foi uma economia nacional híbrida, onde o arcaico e o moderno coexistem, adaptando o sistema econômico às estruturas de uma economia capitalista diferenciada, mas periférica e dependente. Desta forma, articulou-se o setor pré-capitalista com o urbano-comercial, organizando um fluxo de renda que favoreceu o uso do excedente econômico nas duas direções. Conforme apresentado pelo autor:

Só o capitalismo dependente permite e requer tal combinação do "moderno" com o "arcaico", uma descolonização mínima, com uma modernização máxima. Sob esse aspecto, a mencionada acomodação tanto pode ser encarada como "historicamente necessária" quanto como "economicamente útil". Ela estendeu os limites da duração de um sistema pré-capitalista de produção, que excluía parcial ou totalmente a produção agropecuária e extrativa da mercantilização do trabalho, em pleno processo de eclosão e de expansão acelerada de um mercado capitalista interno (e, portanto, de um mercado capitalista de trabalho). (FERNANDES, 1976, p. 177, grifos do autor).

Florestan Fernandes (1976) encontra nas relações comerciais e na organização social do trabalho os aspectos que, segundo o autor, evidenciam como a falta de elasticidade da ordem escravocrata e senhorial se relacionava negativamente com a constituição da competição como fator dinâmico. Sua metodologia propõe dividir o comércio em dois núcleos distintos: os negócios de exportação e importação, onde se estabeleciam os padrões de consumo dos estamentos dominantes e vigorava a orientação capitalista típica; e o comércio comum, formado pelos setores de varejo, artesanato e serviços, em que prevalecia uma orientação extracapitalista e espoliativa. A persistência do trabalho escravo no período neocolonial impedia a operação construtiva das forças capitalistas, impossibilitando a universalização e institucionalização de mecanismos de mercado modernos. A mercantilização incompleta do trabalho livre significa que o trabalhador não ingressava por inteiro no mercado, preservando os entraves que inviabilizariam sua transformação no próprio cerne da vida econômica. Consequentemente, os ramos de atividades comerciais inseridos no núcleo capitalista do mercado interno foram 
deformados. O homem de negócios aspirava aos mesmos ideais e suplantava o estilo de vida da aristocracia agrária, de forma que o burguês representava um "senhor" no mundo da economia urbana, buscando o reconhecimento de seu sucesso em formas arcaicas de diferenciação e de prestígio social. Florestan Fernandes (1976) demonstra que a lógica de dominação senhorial era amplamente reproduzida nas cidades e argumenta que é esse agente - uma forma híbrida de burguês e senhor - que está na raiz da formação do modelo brasileiro de competição.

Em suma, o "protesto burguês", como uma afirmação econômica, social e política revolucionária, não se equacionou historicamente, a partir de manifestações coletivas de condenação da ordem social escravocrata e senhorial ou de exaltação de uma ordem social alternativa. Pela razão muito simples: o agente humano que melhor encarnava a condição burguesa não tramava contra aquela ordem social. Identificava-se com ela, material e politicamente, e só iria abandonar o barco quando ela se mostrasse irremediavelmente inviável (...) esse agente humano interessa seriamente à análise sociológica. É que ele está na raiz da formação do modelo brasileiro de "competição". (FERNANDES, 1976, p. 188).

É na esfera da divisão social do trabalho que estão as marcas mais profundas e duradouras do sistema de produção colonial. A noção de labuta estigmatizava as tarefas mecânicas, assimiladas como forma de perda de dignidade social e de liberdade. Ao não classificar grupos sociais dentro da ordem estamental e de castas, a mercantilização do trabalho colidia com limitações funcionais do mercado colonial e nas imposições do costume, que retiravam o caráter de mercadoria do ofício exercido pelos estratos dominantes. O que se definia como mercadoria na antiga ordem social era o escravo e não o produto de seu trabalho. Consequentemente, a mercantilização do trabalho resistia a se transformar em uma relação habitual, impessoal e desejável. Isso impossibilitou a formação de um mercado de trabalho autêntico concomitante ao mercado de escravos, condenando todos que vendessem sua força de trabalho à superexploração. A expansão do trabalho assalariado não fomentou a competição interna e teve de recorrer à imigração estrangeira, em um processo de associação ao mercado internacional semelhante ao que proporcionou o desenvolvimento capitalista nos centros urbanos. O entrave estrutural ao estabelecimento do trabalho livre obscureceu o processo histórico, retardando a emergência de uma consciência operária e comprometendo o uso legítimo da competição em relações contratuais. Florestan Fernandes (1976) afirma que o trabalho livre foi submetido a um processo de corrupção secular, que negou as condições de solidariedade estamental no antigo regime e retirou as bases estruturais e dinâmicas de sua elaboração como fator social construtivo na ordem social competitiva.

Guardada as proporções, o trabalho livre se configura (como ocorreu com o trabalho escravo), do modo mais cínico e brutal, como puro instrumento de espoliação econômica e de acumulação tão intensiva quanto possível de capital. 
O elemento ou a dimensão humana do trabalho, bem como a "paz social" são figuras de retórica, de explícita mistificação burguesa, e quando precisam ir além disso, o mandonismo e o paternalismo tradicionalistas cedem seu lugar à repressão policial e à dissuasão político-militar. (FERNANDES, 1976, p. 197).

\section{O desenvolvimento como "problema" nacional}

Em uma abordagem sociológica, o conceito de desenvolvimento pode ser visto como a forma histórica decorrente da luta pelo domínio sobre os fatores de desequilíbrio da sociedade de classes (FERNANDES, 2013). Nesta perspectiva, os problemas do Brasil não derivam do crescimento econômico, mas são consequências da maneira que o país se insere no padrão de civilização ocidental. O processo de desenvolvimento deve transformar as relações entre as sociedades pertencentes ao círculo de civilização que estão inseridas, sobretudo com aquelas que detém o comando do processo civilizatório. Como o controle sobre as forças externas escapam o domínio de uma sociedade determinada, particularmente se esta ocupa uma posição dependente, o processo deve ser desencadeado endogenamente através da modificação das estruturas sociais, econômicas e políticas. Portanto, o desenvolvimento é um problema de caráter macrossociológico, relacionado com todas as formas de organização socioeconômicas e condiciona as possibilidades de destino nacional.

O padrão de civilização ocidental se expandiu da Europa para a América por meio do processo de colonização. Consequentemente, os países do Novo Mundo herdaram determinadas instituições, valores sociais e tendências para explorar e desenvolver as potencialidades dessa civilização. O caso brasileiro se caracteriza pela preservação do padrão de civilização transplantado e expansão de sua área de vigência, mas também pela capacidade de conferir-lhe uma feição própria de cunho nacional. A dinâmica da mudança sociocultural no Brasil resulta das contradições do processo de transplantação do padrão de civilização ocidental, decorrentes da incompatibilidade entre as técnicas, instituições e valores sociais com as condições materiais que não puderam ser transferidas, mas que eram necessárias à sua integração estrutural (FERNANDES, 2008c). Para preservar e desenvolver a civilização deslocada, edificou-se uma realidade distinta da europeia, mas capaz de absorver e expandir o padrão civilizatório. A sociedade organizada era capaz de suportar determinado grau de atraso, de forma que o ritmo de renovação sociocultural e econômica fosse regulado pela tensão vinculada ao processo de expansão. A revolução burguesa conferiu as bases materiais necessárias ao desenvolvimento da civilização ocidental, difundindo um novo estilo de vida que reduz a obsolescência através da industrialização.

Embora certas transformações se manifestem em todas as sociedades que compartilham o mesmo padrão de civilização, o progresso das forças produtivas alcançou maior ritmo de 
crescimento em determinados países. Em consequência disso, as sociedades nacionais que possuem condições mais vantajosas para aproveitar as possibilidades de desenvolvimento assumiram o comando do processo civilizatório, concentrando os benefícios materiais, culturais e políticos. As nações que se polarizaram marginalmente assumiram uma posição extremamente desfavorável, ficando subordinados a um crescimento sociocultural controlado de fora e em função de interesses incompatíveis com as necessidades locais. As sociedades dependentes se depararam com entraves para engendrar culturas nacionais integradas, dotadas de relativa autonomia de crescimento interno e de autossuficiência na produção dos dinamismos socioculturais. Florestan argumenta que a raiz de tais problemas decorre da forma incompleta que o regime de classes se objetivou nessas nações, impedindo a formação e o desenvolvimento de controles sociais democráticos (FERNANDES, 2008c). A concentração de riqueza e poder permitiu aos estratos dominantes neutralizar as demais forças sociais, sobretudo no que se refere ao uso do conflito e do planejamento como mecanismo de mudança sociocultural. Ao atingir seus objetivos particulares, as elites assumiram o controle político das transformações e se tornaram fatores de perpetuação do estado crônico de dependência cultural em relação ao exterior.

De acordo com Florestan Fernandes (2008c), o processo de modernização brasileiro não promoveu qualquer forma de crescimento autônomo ou autossustentável, convertendo o país em uma nação subdesenvolvida e dependente. O caráter particular dos desdobramentos históricos expõe as debilidades que a ordem social acarretou ao desenvolvimento do Brasil. A expansão da economia não proporcionou o rompimento das formas sociais obsoletas ou parcialmente modernizadas, responsáveis pela neutralização ou inibição dos efeitos construtivos do crescimento. As condições extraeconômicas constrangeram os fluxos propriamente econômicos da produção e circulação de riqueza, de forma que o padrão de crescimento não forneceu os dinamismos necessários à superação das inconsistências e desequilíbrios socioculturais. Ao se associar às tensões latentes da sociedade, o desequilíbrio político compromete o potencial das forças econômicas, reduzindo ou anulando suas potencialidades e funções sociais construtivas. A posição periférica e dependente engendrou uma economia incapaz de preencher todas as funções necessárias à expansão da civilização transplantada. Nesse sentido, a esfera econômica esvaziouse socialmente e não assumiu o papel de foco central de dinamização do processo civilizatório. A política emerge como fator decisivo em tais condições histórico-estruturais, tomando para si a responsabilidade de regular as consequências dessas debilidades em todas as esferas da vida.

Florestan Fernandes demonstra como o passado colonial resultou em uma sociedade dependente pela análise de seus ciclos revolucionários: o processo de independência e a revolução burguesa (FERNANDES, 2008c). O primeiro ciclo extinguiu o pacto colonial e 
proporcionou a constituição de um Estado nacional politicamente independente, entretanto o controle político foi substituído pela dominação baseada em mecanismos econômicos, reestabelecendo os nexos de dependência através das relações comerciais. O imperialismo econômico orientou as relações entre países centrais e periféricos na fase neocolonial, de forma que a dependência decorria da ordem mundial, na qual as nações marginalizadas se especializaram em funções econômicas vinculadas à dinâmica das economias centrais. $\mathrm{O}$ conjunto de forças atuantes na revolução burguesa ignorou que a expansão interna do capitalismo resultava de ações econômicas exógenas e endógenas, de modo que o poder de determinação dependia dos dinamismos da economia internacional. A industrialização se afirmou como processo de modernização conforme as funções de integração da economia brasileira à mundial se efetivaram. Este processo foi comandado a partir de fora, mas sustentado endogenamente. $\mathrm{O}$ segundo ciclo revolucionário explicita o caráter contraditório do desenvolvimento dependente, pois, ao mesmo tempo que o capitalismo alcança sua maior complexidade na forma industrial, reforçam-se os laços de dependência externa.

A posição das classes na estrutura de poder determina a forma que as mudanças sociais se concretizam historicamente, definindo interesses e valores consagrados ou beneficiados pelas mudanças socialmente necessárias. A sociedade brasileira tendeu para um impasse crônico decorrente do monopólio do controle político pelas elites, impedindo a participação normal e autônoma dos fluxos da civilização ocidental e eternizando a condição de nação dependente. Consequentemente, a mudança social foi deturpada politicamente por interesses particulares ou sobreposta pela estabilidade a todo custo (FERNANDES, 2008c). Os estratos dominantes cumpriram suas funções históricas de maneira invertida, operando como agentes responsáveis por uma especialização que converteu a sociedade em consumidora retardatária e frustrada do progresso sociocultural externo.

Desde que se veja o desenvolvimento como "problema nacional", o diagnóstico e a atuação prática implicam "querer coletivo" polarizado nacionalmente. No caso brasileiro, semelhante polarização tem de ser condicionada, tanto em termos negativos (de repúdio a certos fatores ou efeitos da ordem existente) quanto em termos positivos (de identificação com os objetivos a serem alcançados, através da superação dessa ordem), pelas inconsistências estruturais e dinâmicas que vêm dificultando ou impedindo o Brasil de realizar-se e de desenvolver-se, plenamente, como uma sociedade nacional. (...) A destruição de estamentos e de grupos sociais privilegiados constitui o primeiro requisito estrutural e dinâmico da constituição de uma sociedade nacional. Onde essa condição histórica não chega ou não pode concretizar-se historicamente, também não surge uma ação e, muito menos, uma nação que possa apoiar-se num "querer coletivo" para determinar, por seus próprios meios, sua posição e grau de autonomia entre as demais sociedades nacionais do mesmo círculo civilizatório. Sob esse aspecto, a democratização da renda, do prestígio social e do poder aparece como uma necessidade nacional. É que ela - e somente ela - 
pode dar origem e lastro a um "querer coletivo" fundado em um consenso democrático, isto é, capaz de alimentar imagens do "destino nacional" que possam ser aceitas e defendidas por todos, por possuírem o mesmo significado e a mesma importância para todos (FERNANDES, 2008c, p. 157, grifos do autor).

O desenvolvimento exige uma política econômica que permita eliminar formas de acumulação que onerem improdutivamente a sociedade, corrigindo desequilíbrios regionais e viabilizando a formação de um mercado nacional dinâmico. Entretanto, uma política dessa envergadura pressupõe novas bases da organização e das funções do Estado, redefinindo suas relações com o setor privado e com instituições jurídicas que regulam as atividades econômicas. De acordo com o Florestan Fernandes (2008c), o sistema capitalista só pode conduzir a um processo de independência socioeconômica quando existe uma vontade afirmada coletivamente que tenha como objetivo maior a construção de uma nação autônoma. $\mathrm{O}$ autor argumenta que o Brasil não possui elites capazes de implantar um projeto de desenvolvimento genuinamente nacional, ao mesmo tempo que as massas não se projetaram no cenário histórico como agentes de mudanças sociais conscientemente almejadas em escala coletiva. A superação da condição de subdesenvolvimento exige confrontar características estruturais contraditórias que se perpetuaram ao longo de nossa história, de forma que tal objetivo só pode ser alcançado através da superação da ordem social vigente.

\section{Considerações finais}

A trajetória de Florestan Fernandes é marcada pela notável excelência acadêmica e pelo compromisso com a edificação das bases científicas da sociologia no Brasil. Suas reflexões compreendem profundamente os grandes problemas nacionais, desenvolvendo com maestria as questões levantadas pela geração de intelectuais da década de 1930, chamados "intérpretes do Brasil". Ao tratar dos aspectos de formação da identidade nacional em uma perspectiva especificamente sociológica, sua obra adquire caráter atemporal e de absoluta relevância para a compreensão de fenômenos observados na sociedade contemporânea. Florestan se preocupou em estudar o desenvolvimento capitalista nacional, desvendando a dramaticidade de um capitalismo periférico incapaz de reproduzir as formas sociais plenas do padrão de civilização ocidental moderno característico dos países centrais.

O pensamento de Florestan Fernandes enriquece a reflexão sobre a problemática da identidade brasileira colocada pela geração da década de 1930. O debate aberto por Gilberto Freyre (1996) em Casa-Grande \& Senzala assume nova forma em A integração do negro na sociedade de classes, discorrendo sobre a questão racial e a anomia da população negra como expressão do não aproveitamento das possibilidades históricas abertas pela abolição da 
escravatura. O Sentido da Colonização, apresentado por Caio Prado Júnior (1981) em Formação do Brasil Contemporâneo, é expandido por Florestan ao descrever o processo de ampliação da mais-valor absoluto através de uma divisão do trabalho incipiente e demonstrar como o pacto colonial garantia a realização do excedente acima da Colônia, situação que se inverteu com a internalização da acumulação no período neocolonial, permitindo que a ordem social escravocrata e senhorial alcançasse todas as suas potencialidades. Ao discorrer sobre os problemas de transplantação da civilização ocidental como parte de nossa herança colonial, Florestan explica o que Sérgio Buarque de Holanda (1920) descreveu como "o hábito de macaquear tudo quanto é estrangeiro", resultante da questão de dependência sociocultural.

A Revolução Burguesa no Brasil é a obra que permite inserir definitivamente Florestan Fernandes na categoria de intérprete, dada a profundidade da reflexão referente à formação da sociedade brasileira, além da adoção do estilo ensaístico consagrado pela geração modernista. O livro trata do dilema da democracia na sociedade capitalista, decorrente do funcionamento pleno da ordem social competitiva. Florestan constata que o desenvolvimento histórico da sociedade brasileira não engendrou uma burguesia capaz de instaurar efetivamente o sistema capitalista no país. Isso se deu graças à mecanismos endógenos que impediram a superação de um capitalismo subordinado ao exterior, perpetuando as condições de dependência. Sua análise demonstra como atores decisivos em determinados momentos da história não foram capazes de assumir as funções que deveriam cumprir. Consequentemente, as oportunidades de efetivação do capitalismo foram perdidas, fazendo com que o passado, presente e o futuro coexistam e se interpenetrem de forma indissolúvel.

A raiz dos problemas nacionais está nas incongruências estruturais e dinâmicas que mitigam as potencialidades e funções sociais construtivas do crescimento econômico e impedem o Brasil de se desenvolver como nação. Para Florestan Fernandes, problemas nacionais são desajustamentos reconhecidos como "situações problemáticas" pela sociedade e pelos grupos que possuem o poder de decisão política. Governos enfrentam questões reais e determinadas, mas seu diagnóstico e atuação dependem da possibilidade de se preservar enquanto poder. Por esse motivo, as particularidades da questão são transformadas para que assumam um significado compatível com a vontade popular, mascarando ideologicamente os problemas reais e os substituindo por falsos problemas (BOLAFFI, 1982). Os processos políticos se desdobram como se direitos e garantias sociais fossem privilégios dos estratos que possuem condições econômicas, sociais e políticas para usufruí-los e como se fosse indiferente, para o futuro de nossa sociedade, que o restante da população esteja excluído de suas estruturas de poder. Como demonstrado por Florestan Fernandes, nenhuma sociedade pode construir um destino nacional em tais bases. Desta forma, a superação das disparidades históricas de renda, prestígio social e 
poder político emergem como questões nacionais legítimas, capazes de desencadear um processo de desenvolvimento verdadeiramente democrático.

\section{Referências}

ARRUDA, Maria Arminda. A sociologia de Florestan Fernandes. Tempo Social, São Paulo, v. 22, n. 1, p. 9-27, 1 jun. 2010.

BOLAFFI, Gabriel. Habitação e urbanismo: o problema e o falso problema. In: MARICATO, Ermínia (org.) A produção capitalista da casa (e da cidade) no Brasil industrial. 2. ed. São Paulo: Editora Alfa-Omega, 1982.

COHN, Gabriel. Padrões e dilemas: o pensamento de Florestan Fernandes. In: MORAES, Reginaldo; ANTUNES, Ricardo; FERRANTE, Vera (org.) Inteligência brasileira. São Paulo: Brasiliense, 1986.

FERNANDES, Florestan. A Revolução Burguesa no Brasil: Ensaio de Interpretação Sociológica. 2. ed. Rio de Janeiro: Zahar, 1976.

FERNANDES, Florestan. Circuito fechado: quatro ensaios sobre o poder institucional. São Paulo: Globo, 2005.

FERNANDES, Florestan. A integração do negro na sociedade de classes: o legado da "raça branca". v. 1, 5. ed. São Paulo: Globo, 2008a.

FERNANDES, Florestan. A integração do negro na sociedade de classes: no limiar de uma nova era. v. 2, 5. ed. São Paulo: Globo, 2008b.

FERNANDES, Florestan. Sociedade de classes e subdesenvolvimento. São Paulo: Global, 2008c.

FERNANDES, Florestan. Mudanças sociais no Brasil: Aspectos do desenvolvimento da sociedade brasileira. São Paulo: Global, 2013.

FREITAG, Bárbara. Florestan Fernandes: revisitado. Estudos Avançados, São Paulo, v. 19, n. 55, p. 229-243, set./dez. 2005.

FREYRE, Gilberto. Casa-Grande \& Senzala: formação da família brasileira sob o regime da economia patriarcal. 31. ed. Rio de Janeiro: Record, 1996.

HOLANDA, Sérgio Buarque de. Ariel. Revista do Brasil, São Paulo, v. 53, n. 15, p. 85-87, maio 1920.

PRADO JÚNIOR, Caio. Formação do Brasil Contemporâneo. São Paulo: Brasiliense, 1981.

Recebido em 13/05/2020 - Aprovado em 25/07/2020. 